\title{
EL NUEVO RÉGIMEN JURÍDICO DE LOS CONTRATOS A DISTANCIA ${ }^{144}$
}

\author{
The new legal regime of distance contracts
}

\section{Manuel Pino Abad}

Profesore de la Universidad de Córdoba. E-mail: ad1piabm@uco.es

\section{José Manuel Serrano Cañas}

Profesore de la Universidad de Córdoba. E-mail: jose24mayo@yahoo.es

\section{RESUMEN}

El presente trabajo tiene como finalidad principal exposición pormenorizada del nuevo régimen jurídico de los contratos celebrados a distancia. Como consecuencia de la promulgación de la Ley 3/2014, de 27 de marzo, por la que se modifica el texto refundido de la Ley General para la Defensa de los Consumidores y Usuarios y otras leyes complementarias, se ha dado una nueva redacción al Título III del Libro II del TRLGDCU (artículos 92 a 112). El contenido de estos artículos se adapta fielmente al texto de la Directiva 2011/83/UE.

Palabras clave: Consumidor. Contratos a distancia. Deberes de información. Derecho de DEsistimiento.

\section{Abstract}

This paper work has as main purpose to detailed exposition of the new legal regime of distance contracts. As a consequence of the publication of the Law $3 / 2014,27$ th March, that approved the text of the Law for the Defence of Consumers and Users and other complementary laws, has given a new wording to the Title III of Book II of TRLGDCU (articles 92 to 112). These articles faithfully adapts the text of Directive 2011/83/EU.

\footnotetext{
${ }^{144}$ Este trabajo se enmarca dentro del Proyecto de Investigación de Excelencia "Contratación mercantil y Competencia empresarial: nuevas tendencias reguladoras y propuestas de conexiones normativas" (referencia DER2013-43674-P), financiado por el Ministerio de Economía y Competitividad y del que son Investigadores Principales los Profesores Miranda Serrano y Pagador López.
} 
Keywords: Consumers. Distance contracts. Duty of disclosure. Disclosure DUTIES. RIGHT OF WITHDRAWAL.

SUMARIO: I. Introducción a los contratos a distancia 1. La represión de las prácticas agresivas como fundamento de la tutela legal. 2. Causas justificativas del tratamiento normativo de los contratos a distancia. II.La regulación legal de los contratos a distancia: la transposición de la directiva 2011/83/UE. III. Delimitación del ámbito subjetivo y objetivo de los contratos a distancia. 1 . Delimitación subjetiva del ámbito de aplicación de los contratos a distancia. 2. Delimitación objetiva del ámbito de aplicación de los contratos a distancia. 2.1. Sistema organizado de contratación a distancia. 2.2.- Empleo de técnicas de comunicación a distancia. 3. Contratos excluidos del ámbito de aplicación de los contratos a distancia. IV. Nuevo régimen jurídico de los contratos celebrados a distancia. 1. Los deberes de información precontractual y de confirmación del contrato. 1.1. Requisitos formales de las obligaciones de información precontractual y de confirmación del contrato.1.2. Contenido de la información precontractual.1.3. Consecuencias del incumplimiento de los deberes de información precontractual y de confirmación del contrato. 2. La facultad de desistimiento del consumidor. 2.1. Fundamentación y naturaleza jurídica del derecho de desistimiento en los contratos celebrados a distancia. 2.2. Duración y cómputo del plazo de desistimiento. 2.3. Forma de desistimiento. 2.4. Prueba del desistimiento. 2.5. Consecuencias derivadas del ejercicio de la facultad de desistimiento. 2.6. Consecuencias derivadas del ejercicio de la facultad de desistimiento sobre los contratos complementarios. 2.7.-Excepciones al derecho de desistimiento. 3. Ejecución de los contratos celebrados a distancia. Bibliografía.

\section{INTRODUCCIÓN A LOS CONTRATOS A DISTANCIA}

\section{LA REPRESIÓN DE LAS PRÁCTICAS AGRESIVAS COMO FUNDAMENTO DE LA TUTE- LA LEGAL}

Desde sus orígenes, el Derecho de los consumidores ha tenido como principal finalidad la salvaguarda de la libre formación de la autonomía decisional del consumidor en el momento de prestar su consentimiento contractual. Este principio tuitivo se hace presente en muchas de las normas que integran este sector del ordenamiento jurídico ${ }^{145}$. Con tal fin, este entramado normativo intenta reprimir

${ }^{145}$ Sirva a modo de ejemplo, sin ánimo de exhaustividad, la individualización de prácticas 
aquellas prácticas comerciales agresivas que de forma directa causan una merma (cuando no un verdadero vicio) del consentimiento negocial, atentando contra la libertad contractual, o bien, más sibilinamente, aprovechan situaciones de grave debilidad negocial o de insuficiente (o deficiente) formación de la voluntad para incrementar el volumen de facturación.

Como siempre, los nuevos hechos, reclaman un nuevo derecho. Y la aparición y auge de las comunicaciones comerciales a distancia (reforzada ahora por la consolidación del empleo de Internet como herramienta usual en nuestras relaciones comerciales) suponen un nuevo hecho que necesita un nuevo derecho. El auge de prácticas de captación agresiva (por no decir coactiva) de la voluntad decisoria de los consumidores ha provocado, como efecto reflejo, la necesidad de una conveniente respuesta por el legislador. Téngase presente que estas prácticas, además de rozar el ilícito contractual (por vicios del consentimiento), suponen, a su vez, una alteración ilegítima de las reglas de la competencia y del funcionamiento del mercado. La ausencia de que estas prácticas agresivas quedasen impunes a toda sanción jurídica conllevaría que la "mano invisible" no sólo no eliminaría a aquellas empresas cuya actuación sea más que cuestionable, sino que, por el contrario, las premiaría. Por lo tanto, la represión de estas prácticas comerciales agresivas no obedece simple y llanamente a la defensa y protección del consumidor (contratante y contraparte negocial débil), sino que en ella también están en juego los intereses de los restantes competidores así como el interés público al mantenimiento de un libre y leal funcionamiento del mercado.

\section{Causas justificativas del tratamiento normativo de los Contratos a DISTANCIA}

De entre las prácticas/ventas agresivas merecedoras de algún reproche legal, tradicionalmente se han incluido una modalidad específica de contratación: los contratos a distancia. Desde la primera iniciativa legislativa prevista para regular los contratos a distancia (arts. 38 a 48 de la Ley de Comercio Minorista; Directiva 97/7 sobre contratos a distancia), el legislador toma como punto de partida una concepción previa (presupuesto o, sin más, prejuicio) de esta modalidad promotora de la contratación: en estos contratos, el cliente consumidor se encuentra en una situación de especial vulnerabilidad negocial, de indefensión negocial alejado

desleales con consumidores llevada a cabo por la Ley de Competencia Desleal, o de los actos de publicidad ilícita por la Ley General de Publicidad, o la imposición de deberes informativos a los empresarios con carácter previo a la celebración de los contratos con consumidores que se regulan el Texto Refundido de la Ley General de Defensa de los Consumidores y Usuarios, o en el Real Decreto del Derecho de aprovechamiento por turnos de bienes inmuebles, o en el Real Decreto Carta de Derechos de los usuarios de telecomunicaciones electrónicas, o en la Ley del Contrato de Seguro, etc. 
del estándar normal y razonablemente aceptable, fuente, por tanto, de abusos por parte del otro sujeto contratante. A partir de entonces, la doctrina ha tenido ocasión de determinar cuáles son las principales razones por las que se entiende que el consumidor se encuentra en una especial situación de vulnerabilidad negocial. A saber:

En primer lugar, en estos contratos concurre una circunstancia que ha dado en denominarse riesgo de incumplimiento o decepción, esto es, el riesgo de que el cliente reciba un bien o servicio defectuoso o no coincidente con el solicitado ${ }^{146}$. Téngase presente que a diferencia de la contratación presencial o tradicional, en la contratación a distancia, por su propia naturaleza, el consumidor contrata "a ciegas", sin tener la posibilidad real de manipular el producto, cotejarlo, tenerlo entre manos. El consumidor sólo puede conocer las características del producto o servicio contratado a través de las indicaciones y de la presentación comercial elaborada por el empresario. Se da, pues, un serio déficit de información a la hora de perfeccionar el contrato ${ }^{147}$.

En segundo lugar, en esta modalidad suele darse un déficit de reflexión. Al igual que sucede con los contratos fuera de los establecimientos mercantiles, esta modalidad de contratación favorece la celebración de negocios irreflexivos, no suficientemente meditados y faltos de plena consciencia negocial. Pese a que tradicionalmente se entendía que un mismo contrato no puede reunir la doble condición de ser a distancia y, al mismo tiempo, celebrado fuera del establecimiento mercantil del empresario, la Directiva 2011/83/UE rompe esta concepción y aboga por la unificación del régimen jurídico de ambas modalidades contractuales.

\section{LA REGULACIÓN LEGAL DE LOS CONTRATOS A DISTANCIA: LA TRANSPOSICIÓN DE LA DIRECTIVA 2011/83/UE}

El tratamiento legislativo de los contratos a distancia ha sufrido un proceso de evolución en nuestro ordenamiento jurídico. La finalidad perseguida por el legislador (comunitario y patrio) es doble. Por una parte, la tutela de la libre decisión negocial del cliente que contrata a distancia, esto es, de su libertad de saber y de querer a la hora de celebrar contratos. Por otra, la protección de la seguridad, honestidad y lealtad en el tráfico mercantil negociado a distancia. En efecto, el auge de Internet y su uso masivo fuerzan al legislador a establecer los medios necesarios para hacer

\footnotetext{
${ }^{146}$ MIRANDA SERRANO, L. M., «La contratación a distancia de consumo: TRDCU y Directiva 2001/83/UE», en AA.VV., Derecho (privado) de los consumidores, coord. MIRANDA SERRANO, PAGADOR LÓPEZ, Marcial Pons, Madrid, Barcelona, Buenos Aires, 2012, p. 146.

${ }^{147}$ De hecho, el Considerando 37 de la Directiva 2011/83/UE, fija como fundamento del derecho del desistimiento le hecho de que "en las ventas a distancia el consumidor no puede ver los bienes antes de celebrar el contrato".
} 
posible que los sujetos participantes en este nuevo sistema de contratación muestren un grado de confianza equivalente a la confiada en la contratación presencial. La confianza se erige en un valor de primer orden que interesa estatuir en interés tanto de los empresarios y profesionales como en interés de los consumidores ${ }^{148}$.

La Ley 26/1984, General para la Defensa de los Consumidores y Usuarios no introdujo ninguna medida específica de protección para la contratación a través de técnicas de comunicación a distancia. Tuvo que ser Ley 7/1996, de 15 de enero, de Ordenación del Comercio Minorista la que llevara a cabo la primera regulación de los contratos a distancia a nivel estatal (arts. 38 a 48 del capítulo II, del Título III). No obstante, con la promulgación de la Directiva 97/7/CE, en materia de contratos a distancia, el legislador español se vio obligado a modificar el contenido de la primigenia regulación; lo que tuvo lugar mediante la Ley 47/2002, de 19 de diciembre, de reforma de la Ley 7/1996, de 15 de enero, de Ordenación del Comercio Minorista, para la transposición al Ordenamiento jurídico español de la Directiva 97/7/CE en materia de contratos a distancia y para la adaptación de la Ley a diversas Directivas comunitarias.

Esta regulación fue modificada en noviembre de 2007 como consecuencia de la aprobación del Texto refundido de la Ley General para la Defensa de los Consumidores y Usuarios (Real Decreto Legislativo 1/2007). La regulación sobre los contratos a distancia contenida en la LOCM queda vigente aún para la regulación de las relaciones empresariales. Por la disposición derogatoria única del TRDCU se derogan el art. 48 de la LOCM (que establecía el carácter imperativo de las normas de la LOCM reguladoras de los contratos a distancia para los supuestos en que los clientes actuaran en condición consumidora -contratos de consumo-), y la disposición adicional primera de la LOCM que extendía la aplicación de los arts. 38 a 48 LOCM a los contratos de consumo a distancia referentes a la prestación de servicios.

El 11 de noviembre de 2011 se publicó en el Diario Oficial de la Unión Europea, el texto final de la Directiva 2011/83/UE del Parlamento Europeo y del Consejo, de 25 de octubre de 2011, sobre los derechos de los consumidores. Esta nueva Directiva ha modificado la Directiva 93/13/CEE del Consejo y la Directiva 1999/44/CE del Parlamento Europeo y del Consejo sobre cláusulas abusivas y garantías en las ventas de bienes de consumo, y ha derogado las Directivas 85/577/ CEE del Consejo y 97/7/CE del Parlamento Europeo y del Consejo sobre contratos celebrados fuera de los establecimientos mercantiles y a distancia ${ }^{149}$.

La Directiva 2011/83/UE es el resultado de un largo proceso de revisión de las normas de consumo iniciado por la Comisión Europea en 2001, con la publicación del Libro Verde sobre la protección de los consumidores en la UE, cuyo principal objetivo consistía en poner en marcha una amplia consulta pública acerca del rumbo que habría de tomar en el futuro la política comunitaria de defensa de

\footnotetext{
${ }^{148}$ MIRANDA SERRANO, L. M., op. cit., p. 148.

149 http://revista.uclm.es/index.php/cesco/article/view/10/12
} 
los consumidores ${ }^{150}$. Con motivo de la aprobación de la Directiva sobre prácticas comerciales desleales se puso de manifiesto la necesidad de reformar las Directivas de protección de los consumidores existentes, con la finalidad de garantizar la coherencia general del sistema. En el seno de este proceso armonizador, se promulga la Directiva 2011/83/UE, que nace con pretensiones de alcanzar un nivel de armonización máxima o plena en aquellas materias que han sido expresamente contempladas y reguladas $^{151}$. El legislador europeo ha optado por uniformar la regulación de los distintos Estados miembros en el ámbito de los contratos celebrados a distancia y fuera de los establecimientos mercantiles. Por tanto, los diferentes Estados miembros únicamente cuentan con la posibilidad de transponer e incorporar la Directiva, sin que estén facultados para insertar en el acto de transposición niveles de protección distintos de los establecidos por ella. Como consecuencia de esta Directiva, el legislador español ha promulgado la Ley 3/2014, de 27 de marzo, por la que se modifica el texto refundido de la Ley General para la Defensa de los Consumidores y Usuarios y otras leyes complementarias, aprobado por el R.D. Legislativo 1/2007, de 16 de noviembre. Esta Ley ha dado una nueva redacción al Título III del Libro II del TRLGDCU (arts. 92 a 112), cuyo contenido se adapta fielmente, como no podía ser de otra manera, al texto de la Directiva 2011/83/UE.

Ahora bien, la regulación de la LOCM en materia de contratos a distancia continúa vigente. Así pues, los arts. 92 a 112 resultan aplicables a los contratos a distancia de entrega de bienes o de prestación de servicios que merezcan categorizarse como de consumo, esto es, celebrados entre empresarios y consumidores. Al mismo tiempo, los arts. 38 a 48 LOCM rige para las ventas minoristas a distancia que no puedan caracterizarse como de consumo ${ }^{152}$.

${ }^{150}$ COM -2001-, 531 final, p. 2.

${ }^{151}$ En efecto, su art. 4 establece que "los Estados miembros no mantendrán o introducirán, en su legislación nacional, disposiciones contrarias a las fijadas en la presente Directiva, en particular disposiciones más o menos estrictas para garantizar un diferente nivel de protección de los consumidores, salvo disposición en contrario de la presente Directiva".

${ }^{152}$ Además, la contratación a distancia viene completada con dos normas: el RD 1906/99, de 17 de diciembre, por el que se regula la contratación electrónica y telefónica con condiciones generales en desarrollo del art. 5.3 LCGC, aplicable a los contratos a distancia telefónicos y electrónicos celebrados mediante condiciones generales y la Ley de Servicios de la Sociedad de la Información y del Comercio Electrónico. En este sentido, el nuevo art. 94 TRDCU establece que en las comunicaciones comerciales por correo electrónico o cualquier otro medio de comunicación electrónica y en la contratación a distancia de bienes o servicios por medios electrónicos, se aplicará tanto el TRDCU como la normativa específica sobre servicios de la sociedad de la información y comercio electrónico. En caso de contradicción entre ambos cuerpos normativos, el párrafo $2^{\circ}$ del art. 94 acoge el criterio lex specialis derogat lex generalis, y así establece que será preferente la normativa específica sobre servicios de al sociedad de la información y comercio electrónico, con una excepción: contenido y modo de cumplimiento del deber de información precontractual impuesto al empresario en esta 


\section{DELIMITACIÓN DEL ÁMBITO SUBJETIVO Y OBJETIVO DE LOS CONTRATOS A DISTANCIA}

El régimen de los contratos a distancia viene delimitado mediante el empleo de dos criterios delimitadores. A saber: un criterio personal o subjetivo, por una parte, y un criterio material u objetivo, por otra. El estudio de la aplicación del régimen jurídico de los contratos a distancia no sólo tiene interés por meras razones del conocimiento del derecho aplicable (esto es, por razones de seguridad jurídica), sino porque los criterios delimitadores sirven para caracterizar y conceptualizar el sistema de contratación a cuyo modelo responden los contratos a distancia.

\section{Delimitación subjetiva del Ámbito de aplicación de los contratos a DISTANCIA}

Los nuevos artículos 92 y ss. sólo encuentran aplicación cuando estemos ante contratos de consumo (esto es, contratos celebrados entre empresarios y consumidores, art. 92.2 TRDCU). Se sigue así la tradicional empleado por la Directiva 85/577 y continuado por el ya derogado art. 92.1 TRDCU. Tanto el legislador comunitario como el patrio emplean la expresión "contratos celebrados con consumidores y usuarios". Los contratos de consumo se definen como aquellos "realizados entre un consumidor o un usuario y un empresario" (art. 59.1 TRDCU). Los conceptos legales de consumidor y usuario, por un lado, y, por otro, de empresario están positivizados en los artículos 3 y 4 TRDCU. En efecto, según el primero de los artículos citados, "son consumidores o usuarios las personas físicas que actúen con un propósito ajeno a su actividad comercial, empresarial, oficio o profesión" 153 . Mientras que, por mor del art. 4 TRDCU, empresario es "toda persona física o jurídica, ya sea privada o pública, que actúe directamente o a través de otra persona en su nombre o siguiendo sus instrucciones, con un propósito relacionado con su actividad comercial, empresarial, oficio o profesión"154.

\section{Delimitación obJetiva del Ámbito de aplicación de los Contratos a DISTANCIA}

El régimen jurídico de los contratos a distancia se contiene ahora en

modalidad promotora de la contratación.

${ }^{153}$ La Ley 3/2014 también ha incidido en el concepto de consumidor en el sentido de considerar también como tales a "las personas jurídicas y las entidades sin personalidad jurídica que actúen sin ánimo de lucro en un ámbito ajeno a una actividad comercial o empresarial” (párrafo $2^{\circ}$ del art. 3 TRDCU).

${ }^{154}$ La redacción del artículo 4 también se debe al apartado dos del artículo único de la Ley $3 / 2014$. 
la nueva redacción dada a los arts. 92 y ss. TRDCU (cuyo germen normativo se encuentra en la Directiva 2011/83/UE) ${ }^{155}$. La definición de contrato a distancia la encontramos en el art. 2.7) de la Directiva y en el nuevo art. 92.1 TRDCU. Por contratos a distancia se debe entender ahora aquellos celebrados "en el marco de un sistema organizado de venta o prestación de servicios a distancia, sin la presencia física simultánea del empresario y del consumidor y usuario, y en el que se hayan utilizado exclusivamente una o más técnicas de comunicación a distancia hasta el momento de la celebración del contrato y en la propia celebración del mismo".

De una primera lectura de estos dos preceptos, se puede llegar a una primera conclusión. La Directiva 2011/83/UE caracteriza desde un punto de vista material la contratación a distancia como un sistema de contratación consistente en celebrar contratos sin existencia de contacto presencial entre oferentes y aceptantes, esto es, sin presencia física simultánea de las partes contratantes. La emisión de la aceptación, pues, las partes se deben valer en todo momento de técnicas de comunicación a distancia de cualquier naturaleza.

Por tanto todo contrato, cualquiera que sea su modalidad (compraventa, suministro, arrendamiento, etc.) y su objeto (productos -esto es, bienes muebles o inmuebles- o servicios), puede categorizarse como celebrado a distancia. Ahora bien, para que así ocurra deben concurrir los siguientes elementos caracterizadores legalmente establecidos.

\subsection{Sistema ORgANiZADO DE CONTRATACión A DisTANCIA}

La contratación a distancia se configura legalmente como un sistema de contratación alternativo al tradicional (esto es, alternativo al celebrado dentro del establecimiento mercantil, en el que se encuentran presentes física y simultáneamente las partes contratantes). Pero sólo queda incluido dentro de este régimen especial aquel negocio que forme parte de un sistema organizado de contratación. Por sistema organizado de contratación debe entenderse la creación por parte del empresario de una verdadera organización establecida al objeto de la distribución comercial de bienes o servicios en el mercado a través de técnicas de comunicación a distancia de

${ }^{155}$ Es necesario realizar dos interesantes precisiones: La primera es que la normativa de la Directiva y del texto refundido se aplica tanto a los contratos como a las ofertas de contrato realizadas por los consumidores en las mismas circunstancias, letra b). En segundo lugar, han de incluirse las situaciones en las que el comerciante tiene con el consumidor un contacto personal e individual fuera de su establecimiento mercantil, aunque el contrato se celebre posteriormente dentro de él o a través de un medio de comunicación a distancia, letra c), así como las compras realizadas en el curso de una excursión organizada por el comerciante durante la cual éste proporciona y vende los productos a los consumidores, letra d). MIRANDA SERRANO, L., «La Directiva 2011/83/UE sobre derechos de los consumidores: una nueva regulación para Europa de los contratos celebrados a distancia y extramuros de los establecimientos mercantiles», $R c D$, núm. 11, 2012, pp. 90 ss. 
cualquier naturaleza. Este concepto debe incluir los sistemas ofrecidos por un tercero distinto del comerciante pero utilizado por éste, como una plataforma en línea. No obstante, no debe cubrir los casos en que las páginas web ofrecen información solamente sobre el comerciante, sus bienes o servicios y sus datos de contacto (considerando 20 Directiva 2011/83/UE). Así el nuevo art. 95 TRDCU impone a los operadores de las técnicas de comunicación a distancia (esto es, las personas físicas o jurídicas, públicas o privadas, que sean titulares de las técnicas de comunicación a distancia utilizadas por los empresarios) la obligación de procurar que se respeten por parte de los empresarios el nuevo régimen legal de los contratos a distancia

En cualquier caso, no tendrán la consideración de contratos a distancia todos aquellos negocios que, pese a celebrarse a través de medios de comunicación a distancia (esto es, sin contacto presencial entre los sujetos contratantes) revisten carácter meramente ocasional y aislado. Nos referimos a los supuestos de ventas ocasionales celebradas por teléfono, fax o, incluso, correo electrónicos, entre un consumidor y un operador económico pero que carezca de un sistema organizado de contratación a distancia que le permita ofertar sus bienes a distancia y contratar también a distancia con todos sus potenciales clientes, sino que su sistema habitual de contratación sea el presencial o tradicional.

\subsection{EMPLEO de TÉCNICAS dE COMUNICACIÓN A disTANCIA}

La contratación a distancia se presenta como un sistema de contratación conforme al cual los contratos se concluyen a través de técnicas de comunicación a distancia y, por tanto, sin la presencia física simultánea de los sujetos contratantes. Así lo dispone la ley y lo viene sosteniendo tanto la jurisprudencia como la doctrina. Se trata de una contratación entre distantes, esto es, entre sujetos físicamente distanciados que para contratar se valen de técnicas de comunicación a distancia de cualquier naturaleza.

Distinto de los contratos a distancia son los contratos entre distantes o ausentes. En efecto, tradicionalmente el Derecho privado ha conceptualizado un tipo de contratos, caracterizados por una doble confluencia de eventos: un factor físico o geográfico (por el cual, no deben encontrarse físicamente presentes las partes contratantes) y un factor temporal (intervallo temporis) entre el momento en que se emite la aceptación y el instante en que es conocida por el oferente. De tal forma que no se consideran contratos entre distantes o ausentes los realizados a través del teléfono puesto que en esos casos, la oferta y la aceptación negocial tiene lugar de modo instantáneo.

La contratación a distancia sólo tiene lugar exclusivamente cuando se dé el requisito geográfico, esto es, cuando no exista contacto presencial de los sujetos contratantes. Eso sí, esa ausencia de la presencia física inter partes ha de darse tanto en el momento precontractual (fase previa de la celebración del contrato), 
como en el momento mismo de la celebración del contrato. Por tal razón, quedan excluidos del régimen de los contratos a distancia (pero incluido en el régimen de los contratos celebrados fuera de los establecimientos mercantiles) aquellos celebrados mediante un medio de comunicación a distancia pero "inmediatamente después de que haya existido contacto personal e individual con el consumidor y usuario en un lugar que no sea el establecimiento mercantil del empresario, con la presencia física simultánea del empresario y el consumidor y usuario" [nuevo apartado c) art. 92.2 TRDCU]. Como tampoco quedan incluidos en este régimen aquellos cuya contratación haya comenzado utilizando un medio de comunicación a distancia pero que termina celebrándose en el establecimiento mercantil del empresario (considerando 20 Directiva 2011/83/UE).

La fase de ejecución contractual queda, sin embargo, al margen de esta exigencia legal. Así, el hecho de que la ejecución de un contrato no sea a distancia no excluye al contrato en cuestión de la normativa propia de los contratos a distancia, siempre, claro está, que el contrato fuera negociado y concluido a través de técnicas de comunicación a distancia.

Por técnicas de comunicación a distancia, el legislador comunitario y patrio acoge un criterio de permisibilidad muy amplio. Así, el mismo art. 92.1 TRDCU entiende que "entre otras, tienen la consideración de técnicas de comunicación a distancia: el correo postal, Internet, el teléfono o el fax". Lo determinante es que la técnica de comunicación permita transmitir las declaraciones negociales de quienes contratas, siendo, además, indiferente la identidad o coincidencia entre la técnica empleada por el operador económico o profesional y la usada por el consumidor.

En cualquier caso, en la utilización de una técnica de comunicación a distancia, el empresario o profesional deberá cumplir con los deberes establecidos por el nuevo art. 96 TRDCU. A saber:

En primer lugar, debe constar inequívocamente el carácter comercial de la comunicación comercial remitida por el empresario o profesional al consumidor.

En segundo lugar, el empresario deberá precisar explícita y claramente, al inicio de cualquier conversación con el consumidor y usuario, su identidad, o si procede, la identidad de la persona por cuenta de la cual efectúa la llamada, así como indicar la finalidad comercial de la misma. Además, se prohibe realizar llamadas telefónicas comerciales antes de las 9 horas ni más tarde de las 21 horas, ni durante los dias festivos o los fines de semana.

En tercer lugar, se necesitará el consentimiento expreso previo del consumidor y usuario para la utilización por parte del empresario de técnicas de comunicación que consistan en un sistema automatizado de llamadas sin intervención humana o el telefax. En este sentido, se impone a todo empresario o profesional la prohibición de entablar cualquier tipo de comunicación comercial con aquellos consumidores que no figuren en guías de comunicaciones electrónicas disponibles al público, o hubieren ejercido el derecho a que los datos que aparecen en ellas 
no sean utilizados con fines de publicidad o prospección comercial, o solicitado la incorporación a los ficheros comunes de exclusión de envio de comunicaciones comerciales regulados en la normativa de protección de datos personales (siempre, claro está, que no medie consentimiento del interesado). Esta prohibición se completa con el reconocimiento a favor de todo consumidor o usuario del derecho de oponerse a la recepción de ofertas comerciales no deseadas, por teléfono, fax u otros medios de comunicación equivalente, incluso en el marco de una relación preexistente. Para tal fin, se impone al empresario o profesional el deber de informar en cada una de las comunicaciones comerciales de los medios para oponerse a recibirlas. Estos medios deberán ser "sencillos y gratuitos".

En quinto lugar, aquellos casos en que una oferta comercial no deseada se realice por teléfono, las llamadas deberán llevarse a cabo desde un número de teléfono identificable. Cuando el usuario reciba la primera oferta comercial del emisor, deberá ser informado tanto de su derecho a manifestar su oposición a recibir nuevas ofertas como a obtener el número de referencia de dicha oposición. A solicitud del consumidor y usuario, el empresario estará obligado a facilitarle un justificante de haber manifestado su oposición que deberá remitirle en el plazo más breve posible y en todo caso en el plazo máximo de un mes.

El emisor estará obligado a conservar durante al menos un año los datos relativos a los usuarios que hayan ejercido su derecho a oponerse a recibir ofertas comerciales, junto con el número de referencia otorgado a cada uno de ellos, y deberá ponerlos a disposición de las autoridades competentes.

Por último, el empresario deberá cumplir las disposiciones vigentes sobre protección de los menores y respeto a la intimidad. Cuando para la realización de comunicaciones comerciales se utilicen datos personales sin contar con el consentimiento del interesado, se proporcionará al destinatario la información que señala el artículo 30.2 de la Ley Orgánica 15/1999, de 13 de diciembre, de Protección de Datos de Carácter Personal, y se ofrecerá al destinatario la oportunidad de oponerse a la recepción de las mismas.

\section{Contratos ExCluidos del ÁMbito de APLiCACión DE LOS CONTRATOS A Dis- TANCIA}

Al igual que en la antigua regulación de los contratos a distancia y de los contratos fuera de los establecimientos mercantiles, la Directiva 2011/83/UE y el nuevo art. 93 excluyen de la especial protección algunos contratos que no reúnen los elementos que caracterizan a la contratación celebrada fuera de los establecimientos mercantiles. El legislador comunitario, a tal fin, se ha servido de varios criterios.

En primer lugar, se excluyen por un criterio material u objetivo (esto es, por razón de la naturaleza del objeto sobre el que verse el contrato) los siguientes contratos: 
- Los contratos de servicios sociales, incluidos la vivienda social, el cuidado de los niños y el apoyo a familias y personas necesitadas, temporal o permanentemente, incluida la atención a largo plazo [art. 93 a)]. A juicio de la Exposición de Motivos de la Directiva 2011/83/UE, estos contratos poseen "unas características bien diferenciadas que se reflejan en la legislación específica del sector, de la cual, una parte se decide a nivel de la Unión y otra, a nivel nacional" (Considerando 29).

- Los contratos de servicios relacionados con la salud, prestados por un profesional sanitario a pacientes para evaluar, mantener o restablecer su estado de salud, incluidos la receta, dispensación y provisión de medicamentos y productos sanitarios, con independencia de que estos servicios se presten en instalaciones sanitarias [art. 93 b)]. Estos contratos son excluidos puesto que para la Directiva 2011/83/UE demandan una regulación especial "debido a su complejidad técnica, su importancia como servicio de interés general y su importante financiación pública" (Considerando 30).

- Los contratos de servicios financieros [art. 93 d)], viajes combinados, las vacaciones combinadas y los circuitos combinados regulados en esta ley [art. $93 \mathrm{~g}$ )], así como aquellos determinados aspectos de los contratos de aprovechamiento por turno de bienes de uso turístico, de adquisición de productos vacacionales de larga duración, de reventa y de intercambio regulados en la Ley 4/2012, de 6 de julio, de contratos de aprovechamiento por turno de bienes de uso turístico, de adquisición de productos vacacionales de larga duración, de reventa y de intercambio y normas tributarias [art. 93 h)]. La razón de su exclusión resulta obvia. Estos contratos cuentan con su regulación específica. Rige, por tanto, el principio general del Derecho por el cual la norma del sector específico prevalece sobre el régimen del Testo refundido (normal general).

- Los contratos de creación, adquisición o transferencia de bienes inmuebles o de derechos sobre los mismos [art. 93 e)], así como los contratos para la construcción de edificios nuevos, la transformación sustancial de edificios existentes y el alquiler de alojamientos para su uso como vivienda [art. $93 \mathrm{f}$ )].

- Los contratos de servicios de transporte de pasajeros, sin perjuicio de la aplicación del artículo 98.2 [art. $93 \mathrm{k}$ )].

En segundo lugar, se excluyen en atención a un criterio circunstancial, esto es, por razón de las concretas circunstancias concurrentes en su celebración, los contratos siguientes:

- Los contratos que, con arreglo a la legislación vigente, deban celebrarse ante un fedatario público, obligado por ley a ser independiente e imparcial y a garantizar, mediante el suministro de una información jurídica comprensible, que el consumidor y usuario celebra el contrato únicamente previa reflexión suficiente y con pleno conocimiento de su alcance jurídico [art. 93 i)].

- Los contratos celebrados mediante distribuidores automáticos o 
instalaciones comerciales automatizadas [art. 93 1)].

- Los contratos celebrados con operadores de telecomunicaciones a través de teléfonos públicos para la utilización de esos teléfonos, o celebrados para el establecimiento de una única conexión de teléfono, Internet o fax por parte de un consumidor y usuario [art. $93 \mathrm{~m}$ )].

La exclusión de la normativa específica viene justificada por cuanto que, en ellos, queda eliminado tanto el elemento sorpresivo como la presión psiconegocial del empresario. En efecto, ya desde la primera Ley reguladora de los contratos a distancia (la Ley 26/1991, de 21 de noviembre), se excluían el primer tipo de contratos (los contratos documentados notarialmente) por entender que la información preventiva que el notario ofrece al consumidor diluye los riesgos inherentes a los contratos a distancia. En cambio, el origen las dos exclusiones siguientes ya lo encontramos en la Directiva 97/7/CE, en cuyo art. 3 se excluía de su ámbito de aplicación los negocios celebrados mediante distribuidores automáticos o locales comerciales automatizados (como, por ejemplo, los contratos concluidos en máquinas expendedoras de bebidas, alimentos, juguetes o periódicos) y los concluidos con los operadores de telecomunicaciones debido a la utilización de los teléfonos públicos.

En tercer lugar, la Directiva emplea un criterio mixto (en parte objetivo y en parte circunstancial) para excluir algunos negocios de su ámbito de aplicación. Nos encontramos, en efecto, con una serie de supuestos específicos de exclusión cuya causa estriba en la combinación de un criterio objetivo y uno circunstancial. Así, concretamente, quedan excluidos los contratos para el suministro de productos alimenticios, bebidas u otros bienes de consumo corriente en el hogar (criterio objetivo), suministrados físicamente por un empresario mediante entregas frecuentes y regulares en el hogar o lugar de residencia o de trabajo del consumidor y usuario (criterio circunstancial) [art. 93 j)]. El origen de esta exclusión se encuentra en la Directiva $85 / 577 / \mathrm{CE}$, por cuyo art. 3.2 b) se descartaba a "los contratos relativos a la entrega de productos alimenticios, de bebidas o de otros bienes del hogar de consumo corriente suministrador por distribuidores que realicen viajes frecuentes $y$ regulares". La exigencia de que tales bienes sean suministrados de forma regular excluye el elemento de la sorpresa propio de este sistema de contratación. Al mismo tiempo, quedan excluidos los contratos de actividades de juego por dinero (criterio objetivo) que impliquen apuestas de valor monetario en juegos de azar (criterio circunstancial), incluidas las loterías, los juegos de casino y las apuestas [art. $93 \mathrm{c}$ )]. Para la Directiva (Considerando 31), estos contratos deben contar con una específica regulación de protección de los consumidores, de carácter más estricto.

Porúltimo, se hace necesario destacar la desaparición del criterio cuantitativo como elemento de exclusión del régimen legal de los contratos a distancia. En efecto, el ya derogado art. 108 b) TRDCU excluía la protección de los contratos a distancia a aquellos contratos en los que la cuantía de la prestación total a cargo del consumidor 
fuera inferior a 40,08 euros. En este punto, la Directiva 2011/83/UE facultaba a los Estados miembros a no aplicar sus normas o disposiciones nacionales equivalentes a los contratos a distancia en los que el pago que debe efectuar el consumidor no fuera superior a 50 euros (art. 3.4). Es más, habilitaba a los Estados miembros a definir un valor inferior en sus legislaciones nacionales. No obstante, nuestro legislador español no ha hecho uso de esta facultad y no aparece ningún criterio cuantitativo como excluyente de la aplicación de los arts. 92 y ss. TRDCU. Se elimina así la picaresca consistente en la práctica de ofrecer al consumidor en una misma relación un conjunto de productos o servicios cuyo importe total sea superior a los $50 €$, pero cuyos precios individuales, esto es, fijados por separado, sean inferiores a dicha cifra. Por tal razón, el ya derogado art. 108 b) TRDCU establecía que, a los efectos de computar el importe de los 40,08 € determinantes de la exclusión del contrato, "se considerará como prestación total la suma de todas las correspondientes a cada uno de los contratos celebrados por el consumidor y usuario con ocasión de uno de los actos o en algunas de las circunstancias a que se refiere el artículo anterior". Por tanto, el nuevo régimen legal de los contratos a distancia se aplica a todos los negocios, independientemente de la cuantía que el consumidor tenga que satisfacer en concepto de precio.

En cambio, sí se prevé una presunción legal de inclusión. Así, por mor del art. 92.4 TRDCU, todos los contratos y ofertas celebrados fuera del establecimiento mercantil se presumen sometidos al régimen tuitivo de los contratos a distancia. Se trata de una presunción iuris tantum, que admite prueba en contrario. En este caso, corresponde al empresario probar la no aplicación de las normas reguladoras de la contratación celebrada fuera de los establecimientos mercantiles, por estar incurso en algunas de las excepciones contempladas por el nuevo art. 93 TRDCU.

\section{NUEVO RÉGIMEN JURÍDICO DE LOS CONTRATOS CELEBRADOS A DISTANCIA.}

\section{LOS DEBERES DE INFORMACIÓN PRECONTRACTUAL Y DE CONFIRMACIÓN DEL CONTRATO}

\subsection{REQUisitos FORMALES DE LAS OBLIGACIONES DE INFORMACIÓN PRECON- TRACTUAL Y DE CONFIRMACIÓN DEL CONTRATO}

La libertad de elección del consumidor a la hora de celebrar un contrato depende directamente de que esté debidamente informado acerca de la naturaleza y características de la prestación objeto del contrato y de las condiciones jurídicas y económicas del mismo. Esta es, fundamentalmente, la razón que justifica la imposición, por parte del TRDCU, a los empresarios de la necesidad de cumplir determinados requisitos formales a la hora de contratar con consumidores y usuarios. 
A tenor de lo dispuesto en los arts. 97,1 y 98 TRDCU, el empresario, antes de que el consumidor o usuario quede vinculado por cualquier contrato celebrado a distancia o por cualquier oferta, deberá facilitar a éste de forma clara y comprensible la información precontractual prevista en el art. 97,1.

Dicha información, deberá ser proporcionada, o bien puesta a disposición del consumidor, por parte del empresario, al menos en castellano así como en la lengua utilizada en la propuesta de contratación o, en su caso, en la lengua elegida para la contratación, de forma acorde con las técnicas de comunicación a distancia utilizadas, en términos claros y comprensibles y siempre respetando, en particular, el principio de buena fe en las transacciones comerciales, así como los principios de protección de quienes sean incapaces de contratar. Así pues, no se configura ningún soporte como medio preferente para facilitar la información precontractual legalmente exigida, sino que, por contra, la elección de un determinado medio o soporte dependerá de su adecuación a las técnicas de comunicación a distancia empleadas, si bien siempre que se emplee un soporte duradero para proporcionar dicha información, éste habrá de ser legible (art.98,1 TRDCU).

Por soporte duradero, a los efectos aquí analizados, habrá que entender, según se infiere de la Directiva 2011/83/UE, todo instrumento que permita al consumidor o al comerciante almacenar información que se le transmita personalmente de forma que en el futuro pueda recuperarla fácilmente durante un periodo de tiempo acorde con los fines de dicha información y que permita la reproducción de la información almacenada sin cambios. Así pues, podemos considerar que cumplen los requisitos exigidos la información suministrada en papel, memoria USB, CD-ROM, DVD, tarjetas de memoria, discos duros de ordenador, email, entre otros soportes.

No obstante, como ya hemos afirmado, el TRDCU no exige que en todo caso la información precontractual se proporcione al consumidor mediante el empleo de algún soporte duradero. Así, cuando el contrato se celebre a través de alguna página Web, la información precontractual podrá facilitarse al consumidor en línea sin necesidad de emplear soporte duradero alguno siempre que se le permita archivar las condiciones generales aplicables a la contratación (art. 27,4 Ley 34/2002, de 11 de julio, de Servicios de la Sociedad de la Información). Igualmente, si el contrato se celebra por vía telefónica, se podrá proporcionar la información principal por teléfono y remitir al consumidor a otro medio complementario (página Web, email, correo postal, etc) a fin de que pueda ampliar la información recibida.

Por el contrario, a diferencia de lo que acontece con la información precontractual legalmente exigida, el art.98,7 del TRDCU sí exige, en todo caso, que el empresario facilite al consumidor la confirmación del contrato celebrado en un soporte duradero dentro de un plazo razonable tras la celebración del mismo y, a lo sumo, en el momento de la entrega de los bienes, o bien, del inicio de la ejecución del servicio objeto del contrato a distancia celebrado. Tal confirmación incluirá toda la información que figura en el artículo 97.1, salvo en el supuesto de que el empresario 
ya la hubiese facilitado al consumidor en un soporte duradero antes de la celebración del contrato a distancia, y, además, en su caso, la confirmación del previo consentimiento expreso del consumidor y del conocimiento por su parte de la pérdida del derecho de desistimiento de conformidad con el art.103.m) del TRDCU.

En el supuesto de que se trate de contratos celebrados por medios electrónicos que impliquen obligaciones de pago para el consumidor, se imponen al empresario especiales exigencias respecto al contenido, al momento y a la forma de la información precontractual que debe proporcionar al consumidor. Concretamente, el art.98,2 TRDCU obliga al empresario a que, en estos casos, ponga en conocimiento del consumidor, de manera clara y destacada y justo antes de que efectúe su pedido, al menos la información principal establecida en los apartados a), e), p) y q) del art.97,1 y que se refieren a las características y precio de los bienes y servicios ofertados, así como a la duración del contrato y de las obligaciones del consumidor. Por tanto, en estos supuestos no bastará con que el empresario ponga a disposición del consumidor, de forma acorde con las técnicas de comunicación a distancia empleadas, la información requerida por el art.97,1 TRDCU, es decir, no será suficiente con la indicación de un enlace que el consumidor pueda visitar para informarse sobre las condiciones del contrato, sino que, en estos casos, el empresario estará obligado a poner en conocimiento del consumidor, y con anterioridad a la realización del pedido, al menos la información principal del contrato antes citada.

Además, el mismo art. 98,2 exige que, con la finalidad de que el consumidor sea consciente de la obligación de pago que asume, confirme expresamente, en el momento de efectuar su pedido, que es consciente de que el pedido realizado implica una obligación de pago. Por esta razón, si la realización del pedido se hace activando un botón o una función similar, éstos deberán etiquetarse, de manera que sea fácilmente legible, con la expresión "pedido con obligación de pago» o una formulación análoga no ambigua que indique que la realización del pedido implica la obligación de pagar al empresario. En caso contrario, el consumidor y usuario no quedará obligado por el contrato o pedido.

Con la misma finalidad de incrementar al alza las exigencias informativas en los contratos electrónicos, las web de comercio electrónico "deberán indicar" (no sólo facilitar información remitiendo a otros enlaces informativos), de modo claro y legible (tamaño de letra adecuado, información fija y no en formato flash), "a más tardar al inicio del procedimiento de compra" si se aplican algunas restricciones de entrega (ej. en función de la distancia o de los gastos de transporte y entrega) y cuáles son los medios de pago aceptados y su eventual coste.

En los supuestos en los que el contrato se celebre a través de una técnica de comunicación a distancia en la que el espacio o el tiempo para facilitar la información sean limitados (p.ej. vía telefónica, SMS, restricción del número de caracteres por pantalla reducida, anuncio de televisión o radio, etc), el empresario deberá facilitar, con anterioridad a la celebración del contrato y en ese soporte 
especifico, como mínimo la información precontractual sobre las características principales de los bienes o servicios, la identidad del empresario, el precio total, el derecho de desistimiento, la duración del contrato y, en el caso de contratos de duración indefinida, las condiciones de resolución, tal como se refiere en el artículo 97.1. a), b), e), i) y p). El resto de la información prevista en el art.97,1 del TRDCU deberá ser facilitada al consumidor de una manera apropiada a la técnica de comunicación empleada (p.ej. remisión a una web con la información completa sobre el servicio y a solicitud del interesado, número telefónico o envío en soporte papel $\mathrm{u}$ otro soporte duradero de todas las condiciones aplicables al contrato) (art.98,4 TRDCU).

Sin perjuicio de lo dispuesto en el comentado art.98,4 en relación con los deberes informativos del empresario cuando el contrato se celebre a través de una técnica de comunicación a distancia en la que el espacio o el tiempo para facilitar la información sean limitados, si el contrato se celebrara por vía telefónica, el empresario deberá revelar, al inicio de la conversación, su identidad o, en su caso, la identidad de la persona por cuenta de la cual efectúa la llamada e indicar el objeto comercial de la misma. Así mismo, deberá confirmar la oferta al consumidor por escrito, o salvo oposición del mismo, en cualquier soporte de naturaleza duradera, no resultado vinculado el consumidor hasta que haya aceptado la oferta mediante su firma o mediante el envio de su acuerdo por escrito (email, fax o SMS) (art.98, 5 y 6 TRDCU).

Por último, según dispone el art.98,9 TRDCU, corresponderá al empresario probar el cumplimiento los deberes de información previstos en el citado precepto, así como, adoptar las medidas adecuadas que permitan identificar inequívocamente al consumidor con el que celebre el contrato.

\subsection{CONTENIDO DE LA INFORMACIÓN PRECONTRACTUAL}

De conformidad con el art.97,1 TRDCU, antes de que el consumidor y usuario quede vinculado por cualquier contrato celebrado a distancia o cualquier oferta correspondiente, el empresario le facilitará de forma clara y comprensible la siguiente prolija información, la cual, además, deberá ser legible y estar redactada al menos en castellano (art.99,1 TRDCU):

a) Las características principales de los bienes o servicios, en la medida adecuada al soporte utilizado y a los bienes o servicios; b) La identidad del empresario, incluido su nombre comercial; c) La dirección completa del establecimiento del empresario y el número de teléfono, número de fax y dirección de correo electrónico del mismo, cuando proceda, con objeto de que el consumidor y usuario pueda ponerse en contacto y comunicarse con él de forma rápida y eficaz, así como, cuando proceda, la dirección completa y la identidad del empresario por cuya cuenta actúa; d) Si es diferente de la dirección facilitada de conformidad con la letra c), la dirección 
completa de la sede del empresario y, cuando proceda, la del empresario por cuya cuenta actúa, a la que el consumidor y usuario puede dirigir sus reclamaciones; e) El precio total de los bienes o servicios, incluidos los impuestos y tasas, o, si el precio no puede calcularse razonablemente de antemano por la naturaleza de los bienes o de los servicios, la forma en que se determina el precio, así como, cuando proceda, todos los gastos adicionales de transporte, entrega o postales y cualquier otro gasto $\mathrm{o}$, si dichos gastos no pueden ser calculados razonablemente de antemano, el hecho de que puede ser necesario abonar dichos gastos adicionales. En el caso de un contrato de duración indeterminada o de un contrato que incluya una suscripción, el precio incluirá el total de los costes por período de facturación. Cuando dichos contratos se cobren con arreglo a una tarifa fija, el precio total también significará el total de los costes mensuales. Cuando no sea posible calcular razonablemente de antemano el coste total, se indicará la forma en que se determina el precio; f) El coste de la utilización de la técnica de comunicación a distancia para la celebración del contrato, en caso de que dicho coste se calcule sobre una base diferente de la tarifa básica; g) Los procedimientos de pago, entrega y ejecución, la fecha en que el empresario se compromete a entregar los bienes o a ejecutar la prestación de los servicios, así como, cuando proceda, el sistema de tratamiento de las reclamaciones del empresario; $h$ ) La lengua o lenguas en las que podrá formalizarse el contrato, cuando ésta no sea la lengua en la que se le ha ofrecido la información previa a la contratación; i) Cuando exista un derecho de desistimiento, las condiciones, el plazo y los procedimientos para ejercer ese derecho, así como el modelo de formulario de desistimiento; j) Cuando proceda, la indicación de que el consumidor y usuario tendrá que asumir el coste de la devolución de los bienes en caso de desistimiento y, para los contratos a distancia, cuando los bienes, por su naturaleza, no puedan devolverse normalmente por correo, el coste de la devolución de los mismos; k) En caso de que el consumidor y usuario ejercite el derecho de desistimiento tras la presentación de una solicitud con arreglo al artículo 98.8 o al artículo 99.3, la información de que en tal caso el consumidor y usuario deberá abonar al empresario unos gastos razonables de conformidad con el artículo 108.3 ; 1) Cuando con arreglo al artículo 103 no proceda el derecho de desistimiento, la indicación de que al consumidor y usuario no le asiste, o las circunstancias en las que lo perderá cuando le corresponda; m) Un recordatorio de la existencia de una garantía legal de conformidad para los bienes; n) Cuando proceda, la existencia de asistencia posventa al consumidor y usuario, servicios posventa y garantías comerciales, así como sus condiciones; o) La existencia de códigos de conducta pertinentes y la forma de conseguir ejemplares de los mismos, en su caso. A tal efecto, se entiende por código de conducta el acuerdo o conjunto de normas no impuestas por disposiciones legales, reglamentarias o administrativas, en el que se define el comportamiento de aquellos empresarios que se comprometen a cumplir el código en relación con una o más prácticas comerciales o sectores económicos; $p$ ) La duración del contrato, cuando proceda, $\mathrm{o}$, si el contrato es de duración indeterminada 
o se prolonga de forma automática, las condiciones de resolución; q) Cuando proceda, la duración mínima de las obligaciones del consumidor y usuario derivadas del contrato; r) Cuando proceda, la existencia y las condiciones de los depósitos u otras garantías financieras que el consumidor y usuario tenga que pagar o aportar a solicitud del empresario; s) Cuando proceda, la funcionalidad de los contenidos digitales, incluidas las medidas técnicas de protección aplicables; t) Cuando proceda, toda interoperabilidad relevante del contenido digital con los aparatos y programas conocidos por el empresario o que quepa esperar razonablemente que éste pueda conocer; u) Cuando proceda, la posibilidad de recurrir a un mecanismo extrajudicial de reclamación y resarcimiento al que esté sujeto el empresario y los métodos para tener acceso al mismo.

\subsection{CONSECUENCIAS DEL INCUMPLimiento DE LOS DEBERES DE INFORMACIÓN PRECONTRACTUAL Y DE CONFIRMACIÓN DEL CONTRATO}

Si el empresario no cumple los requisitos de información sobre gastos adicionales $u$ otros costes contemplados en el apartado 1. e), o sobre los costes de devolución de los bienes contemplados en el apartado 1. j), del art.97 TRDCU, el consumidor no deberá abonar dichos gastos o costes (art.97,6 TRDCU)

Además, si el contrato se hubiese celebrado sin que se hubiese facilitado al consumidor la copia del mismo o su confirmación, de acuerdo con el art.98, 7, podría ser anulado a instancia del consumidor por vía de acción o excepción. Sin embargo, en ningún caso podría ser invocada la causa de nulidad por el empresario, salvo que el incumplimiento fuese exclusivo del consumidor y usuario (art.100 TRDCU).

En todo caso, corresponderá al empresario probar el cumplimiento de las obligaciones formales referidas anteriormente (arts.97,8, 98,9 y 100 TRDCU).

Así pues, el TRDCU impone al empresario la obligación de probar el cumplimiento de sus obligaciones formales con el fin de reforzar la posición jurídicotuitiva del consumidor que participe en estos negocios. En consecuencia, si el consumidor solicitara la anulación del contrato por incumplimiento de los requisitos formales legalmente exigidos ex art.98,7 TRDCU, sería el empresario el encargado de demostrar el cumplimiento de los mismos. Si, por el contrario, fuese el empresario quien solicitara el cumplimiento del contrato, correspondería, en su caso, al consumidor oponer la invalidez del mismo por incumplimiento de los citados requisitos formales. 


\section{LA FACULTAD DE DESISTIMIENTO DEL CONSUMIDOR}

\subsection{FUNDAMENTACIÓN Y NATURALEZA JURÍDICA DEL DERECHO DE DESISTIMIENTO EN LOS CONTRATOS CELEBRADOS A DISTANCIA}

Como es bien sabido, en nuestro Ordenamiento jurídico los contratos, en cuanto fruto del acuerdo entre dos o más voluntades, se perfeccionan, como regla general, por el mero consentimiento y desde entonces obligan no sólo al cumplimiento de lo expresamente pactado sino también a todas las consecuencias que según su naturaleza sean conformes a la buena fe, al uso y a la Ley (art.1.258 C.C). De este modo, las obligaciones que nacen de los contratos adquieren fuerza de Ley entre las partes contratantes (art.1.091 C.C), sin que ninguna de éstas pueda unilateralmente y a su libre albedrío decidir acerca del cumplimiento y la validez de los contratos por ellas celebrados (art.1.256 C.C).

Para nuestro legislador decimonónico el contrato se concibe, pues, como el producto de la actuación libre y espontánea de las partes contratantes que, de este modo, manifiestan su consentimiento contractual de forma seria, espontánea, libre, y desde un plano de igualdad que impide que una de las partes quede sujeta al convenio $y$, entre tanto, la otra reste libre de él. De esta forma, el contrato habrá de considerarse válido y eficaz salvo que, ante la ausencia de alguna de las circunstancias antes aludidas en el consentimiento contractual, se decrete la invalidez del negocio por vicios del consentimiento, o bien las partes decidan por mutuo acuerdo desistir del contrato celebrado entre ambas.

En consecuencia, es posible afirmar que la facultad de desistimiento conferida unilateralmente al consumidor en el TRDCU se presenta, al menos en línea de principio, como una excepción a las reglas generales, antes referidas, de validez y eficacia de los contratos, en cuanto que se concede al consumidor el derecho a separarse de forma unilateral y discrecional del contrato celebrado, pese a no mediar ni un vicio del consentimiento prestado por el mismo, ni un previo acuerdo de resolución contractual con el empresario. En este sentido, este derecho de desistimiento reconocido en favor del consumidor se puede considerar como una verdadera novedad justificada, a nuestro juicio, a tenor del proceso evolutivo de transformación experimentado por el viejo Derecho privado obligado a adaptarse a la siempre cambiante realidad socioeconómica circundante en la que debe aplicarse.

Dado que en los contratos celebrados a distancia el consumidor celebra el contrato sin haber tenido la posibilidad real de ver el producto o de conocer las características del servicio y/o, además, puede verse compelido a contratar afectado por una posible presión psicológica o por un elemento de sorpresa independientemente de que haya solicitado o no el contacto con el empresario, el TRDCU, en sus arts. 102 y s.s., le confiere un derecho de desistimiento que le va a permitir, durante el plazo legalmente previsto, poner fin a la relación contractual previamente nacida 
de forma totalmente discrecional y sin necesidad de que medie justa causa alguna.

De este modo, la facultad de desistimiento del consumidor se configura legalmente como una declaración de voluntad unilateral, recepticia, discrecional y de libre ejercicio. Es unilateral en cuanto que emana de una sola parte y no requiere para producir sus efectos ser aceptada por la otra, -esto es, por el empresario-; se ha de considerar recepticia dado que su eficacia depende de que sea conocida por parte del empresario, con independencia de que ello suceda con posterioridad al plazo de reflexión durante el cual el consumidor tiene la posibilidad de desistir del contrato, puesto que lo realmente importante es que el derecho de desistimiento se ejerza dentro del período de reflexión; se trata, finalmente, de una declaración de voluntad discrecional y de libre ejercicio, en cuanto que permite al consumidor desligarse del contrato válido y perfecto dentro del plazo legal de reflexión si así lo estima oportuno y sin necesidad de que concurra justa causa alguna en la que sustentar su decisión.

En segundo lugar, el derecho de desistimiento se configura como una facultad de carácter imperativo e irrenunciable por parte del consumidor. Por esta razón, su existencia o reconocimiento no resulta negociable por las partes contratantes sino que es consustancial al mismo contrato celebrado fuera del establecimiento mercantil (art.97,5 TRDCU) cualquiera que sea el bien o servicio objeto del mismo (salvo las excepciones previstas en el art.103 TRDCU) y, además, de obligatoria inclusión en el documento contractual, de forma que, la infracción de esta obligación, esto es, la no inclusión en el contrato de la citada cláusula de desistimiento, a parte de no impedir que el comprador posea este derecho, podrá ser sancionada por el Juez competente en la forma prevista en el art.105 TRDCU tal y como después analizaremos.

Por último, este derecho de desistimiento se caracteriza por tener un cierto carácter retroactivo en cuanto que pone fin a un contrato perfectamente válido y carente de vicios, de modo que, obliga a las partes a restaurar la situación anterior a la celebración del contrato y, por consiguiente, a restituirse, recíprocamente entre sí, las prestaciones que previamente se hubiesen intercambiado, desapareciendo los efectos que el contrato hubiera comenzado a producir como si tal contrato nunca hubiese existido (arts.106, 107 y 108 TRDCU)..

\subsection{Duración y Cómputo del Plazo de Desistimiento}

El TRDCU establece en sus arts.102,1, 104 y 105 un plazo de catorce días naturales dentro del cual el consumidor podrá ejercer su derecho de desistimiento del contrato previamente celebrado a distancia. El momento a partir del cual comenzará a computarse el citado plazo será diferente según se trate de contratos que tengan por objeto la prestación de servicios, o bien tengan por objeto la entrega de bienes. Así, mientras que en el primer caso, el art.104 TRDCU establece que el cómputo del plazo comenzará a partir del día de la celebración del contrato, en el segundo, dispone que el plazo de desistimiento comenzará el día en el que el consumidor o un tercero por 
él indicado, distinto del transportista, adquiera la posesión material de los bienes solicitados, o bien: $\mathbf{1 .}^{\mathbf{0}}$ en caso de entrega de múltiples bienes encargados por el consumidor en el mismo pedido y entregados por separado, el día que éste o un tercero por él indicado, distinto del transportista, adquiera la posesión material del último de los bienes; $\mathbf{2 .}^{\circ}$ en caso de entrega de un bien compuesto por múltiples componentes o piezas, el día que el consumidor o un tercero por él indicado, distinto del transportista, adquiera la posesión material del último componente o pieza; y 3. ${ }^{\circ}$ en caso de contratos para la entrega periódica de bienes durante un plazo determinado, el día que el consumidor o un tercero por él indicado, distinto del transportista, adquiera la posesión material del primero de esos bienes.

Sin embargo, excepcionalmente, este plazo general de desistimiento resulta ampliado por el art.105 TRDCU en los supuestos en los que el empresario no facilite al consumidor, en la forma legalmente exigida en el art.97.1.i), la información sobre su derecho a desistir del contrato. En tal supuesto, el periodo de desistimiento finalizaría doce meses después de la fecha de expiración del periodo de desistimiento inicial, determinada de conformidad con el artículo 104. No obstante, si el empresario facilitara al consumidor la citada información en el plazo de doce meses a partir de la fecha contemplada en el artículo 104, el plazo de desistimiento expirará a los 14 días naturales de la fecha en que el consumidor recibiera dicha información.

Sin lugar a duda, consideramos muy acertada la solución de ampliar el plazo para desistir en los supuestos en los que el empresario incumpla en la forma legalmente prevista sus deberes formales de información, por cuanto que ello redundará en una sensible mejora de la confianza de los consumidores en el tráfico mercantil sobre todo si tenemos en cuenta la importancia que tiene la citada información para que el consumidor ejerza su derecho a desistir del contrato. Pese a todo, hubiésemos considerado más acertada la norma si el incumplimiento por parte del empresario de su deber de informar al consumidor acerca de su derecho a desistir del contrato hubiese supuesto no sólo la ampliación del plazo de desistimiento, sino, más bien, la posibilidad de que el consumidor pudiese desistir del contrato entre tanto el empresario cumpliese con su deber de información. Así, lo entendemos pese a que la Directiva 2011/83/UE considerara en su Exposición de Motivos que conviene introducir un plazo de prescripción de doce meses para garantizar la seguridad jurídica, y ello, porque la solución que propugnamos es, en nuestra opinión, la que en mayor grado contribuye a compeler a los empresarios a cumplir con sus deberes de información, al tiempo que es la que mejor ampara los intereses económicos de los consumidores y la tan necesitada confianza en el tráfico mercantil

Por último, debemos tener presente que, según establece el art.106,2 TRD$\mathrm{CU}$, el consumidor habrá ejercido su derecho de desistimiento dentro de los plazos contemplados en los artículos 104 y 105, cuando haya enviado la comunicación relativa al ejercicio del derecho de desistimiento antes de que finalicen dichos plazos. 
Por tanto, para determinar la observancia del plazo para desistir se tendrá en cuenta la fecha de expedición de la declaración de desistimiento, independientemente de cuál sea la fecha concreta en la que la ésta llegue a ser recibida y conocida por el empresario, dado que su eficacia depende de que sea conocida por el empresario, con independencia de que ello suceda con posterioridad al plazo de reflexión durante el cual el consumidor tiene la posibilidad de desistir del contrato, puesto que lo realmente importante es que el derecho de desistimiento se ejerza dentro del período de reflexión.

\subsection{ForMA DE DESISTIMIENTO}

Parece claro que el TRDCU acoge en esta materia el principio espiritualista de libertad de forma, por cuanto que, el consumidor, según establece literalmente el art.106,1 del TRDCU, comunicará al empresario, antes de que venza el plazo de desistimiento, su decisión de desistir del contrato, pudiendo para ello utilizar el modelo de formulario de desistimiento que figura en el anexo B del TRDCU, o bien realizar otro tipo de declaración inequívoca en la que señale su decisión de desistir del contrato (como p. ej. carta, llamada telefónica, fax o, incluso, mediante la devolución de las mercancías recibidas como forma tácita de ejercer el derecho de desistimiento al constituir un hecho concluyente e inequívoco de que el consumidor desea poner fin a la relación contractual con el empresario). Incluso, el párrafo tercero del citado art.106 permite al empresario ofrecer al consumidor la posibilidad de cumplimentar y enviar electrónicamente el modelo de formulario de desistimiento que figura en el anexo $B, o$ cualquier otra declaración inequivoca a través del sitio web del empresario. En tales casos, el empresario comunicará sin demora al consumidor en un soporte duradero el acuse de recibo de dicho desistimiento.

Así pues, lo realmente importante para que el desistimiento del consumidor alcance eficacia jurídica no es la forma empleada por el consumidor para comunicar al empresario su deseo de desistir del contrato con éste celebrado, sino que esa comunicación se haya producido dentro del plazo legalmente previsto y que el consumidor esté en condiciones de acreditar que asi ha acontecido.

Finalmente, consideramos que, a tenor de la libertad de forma impuesta por el legislador en esta materia, cualquier cláusula contractual por la que se le exigiera al consumidor por parte del empresario el cumplimiento de cualquier requisito formal respecto al ejercicio de su facultad de desistimiento, debería reputarse nula y como no puesta.

\subsection{Prueba del desistimiento}

Según establece el art.106,4 TRDCU, la carga de la prueba del ejercicio del derecho de desistimiento recaerá sobre el consumidor, quién deberá probar no sólo el hecho de haber comunicado al empresario su deseo de desistir del contrato 
sino, también, que esa comunicación se ha producido dentro del plazo legalmente previsto.

\subsection{Consecuencias derivadas del EJercicio de la FaCUltad de Desisti- MIENTO}

La principal consecuencia que el ejercicio de la facultad de desistimiento conlleva consiste en que se extinguirán las obligaciones de las partes de ejecutar el contrato celebrado fuera del establecimiento mercantil o, en su caso, de celebrar el mismo, cuando el consumidor haya realizado una oferta (art.106,5 TRDCU). Esto es, según distingue el citado precepto, cuando la declaración de voluntad emitida por el consumidor hubiese tenido por finalidad la aceptación de la oferta realizada por el empresario y, en consecuencia, la perfección del contrato celebrado con éste, el ejercicio de la facultad de desistimiento por parte del consumidor provocará la extinción del contrato y, por ende, de las obligaciones contractuales recíprocamente asumidas por las partes. Sin embargo, cuando el consumidor hubiese hecho al empresario una simple oferta de contrato, el ejercicio de la facultad de desistimiento no provocaría la extinción del contrato puesto que éste nunca habría llegado a perfeccionarse, sino que, tan sólo provocaría la extinción del compromiso asumido por las partes de celebrar el contrato.

La extinción del contrato como consecuencia del ejercicio de la facultad de desistimiento acarreará que las partes se vean compelidas a restituirse recíprocamente las prestaciones ya realizadas como consecuencia de la ejecución del contrato extinto. Así, según se infiere del art.107,1 TRDCU, el empresario deberá reembolsar al consumidor todo pago recibido de éste, incluidos, en su caso, los costes de entrega, sin demoras indebidas y, en cualquier caso, antes de que hayan transcurrido 14 días naturales desde la fecha en que hubiese sido informado de la decisión de desistimiento del contrato por parte del consumidor de conformidad con el art. 106 del TRDCU.

Además, en el supuesto de que el empresario se retrase injustificadamente en la devolución de las sumas abonadas, el consumidor podrá reclamar que se le pague el doble del importe adeudado, sin perjuicio de su derecho a ser indemnizado por los daños y perjuicios sufridos en los que excedan de dicha cantidad.

No obstante, en los contratos de venta con previa entrega de bienes, el empresario podrá retener el reembolso aludido hasta haber recibido los bienes entregados al consumidor, o hasta que éste haya presentado una prueba de la devolución de los mismos, salvo en el caso de que el empresario se haya ofrecido a recoger él mismo los bienes (art.107,3 TRDCU).

Por su parte, tras ejercer su facultad de desistimiento y producirse la extinción del contrato vigente, el consumidor vendrá obligado a devolver al empresario, o a la persona por éste autorizada, los bienes recibidos objeto del contrato celebrado, 
salvo que el propio empresario se ofrezca a recogerlos. Dicha devolución deberá producirse sin ninguna demora indebida y, en cualquier caso, a más tardar en el plazo de 14 días naturales a partir de la fecha en que comunique su decisión de desistimiento del contrato al empresario, de conformidad con el artículo 106 del TRDCU (art.108,1 TRDCU).

No obstante, si los bienes se hubiesen entregado en el domicilio del consumidor en el momento de la celebración del contrato y debido a la naturaleza de los mismos, éstos no pudiesen devolverse por correo, deberá el empresario recogerlos a su propio cargo.

Además, a pesar de la rotundidad con la que se pronuncia el art.73 TRDCU cuando establece que en los contratos celebrados con consumidores "el ejercicio del derecho de desistimiento no implicará gasto alguno para el consumidor y usuario", el consumidor deberá soportar los costes directos de la devolución de los bienes, salvo cuando el empresario hubiese aceptado asumirlos o no hubiese cumplido con su deber de información precontractual al no informar al consumidor de que le correspondería asumir esos costes en caso de ejercer su facultad de desistimiento (art.108,1 TRDCU).

El consumidor también será responsable de la disminución del valor de los bienes derivada de una manipulación distinta a la necesaria para establecer la naturaleza, las características o el funcionamiento de los mismos, salvo en el supuesto de que el empresario no le hubiese informado de su derecho de desistimiento con arreglo al artículo 97.1.i) del TRDCU (art.108,2 TRDCU).

Cuando un consumidor ejerza su derecho de desistimiento tras haber realizado una solicitud expresa de que la prestación de un servicio o el suministro de agua, gas, electricidad o calefacción dé comienzo durante el plazo para desistir, resultará obligado a abonar al empresario un importe proporcional a la parte ya prestada del servicio en el momento en que haya informado al empresario del ejercicio del derecho de desistimiento. El importe proporcional que habrá de abonar al empresario se calculará sobre la base del precio total acordado en el contrato, salvo que dicho precio sea excesivo, en cuyo caso, el importe proporcional se calculará sobre la base del valor de mercado de la parte ya prestada del servicio. Sin embargo, el consumidor no asumirá coste alguno por la prestación de los servicios o el suministro de agua, gas, electricidad o de calefacción durante el período de desistimiento, cuando el empresario no le hubiera facilitado información con arreglo al artículo 97.1.i) o k), o bien, cuando el consumidor no hubiera solicitado expresamente que la prestación del servicio se iniciara durante el plazo de desistimiento con arreglo al art. 98.8 del TRDCU (art.108,3 y 4 TRDCU).

Tampoco asumirá el consumidor gasto alguno por el suministro, en su totalidad o en parte, de contenido digital que no se preste en un soporte material, cuando no hubiese dado expresamente su consentimiento previo a la ejecución antes de la finalización del periodo de 14 días naturales contemplado en el artículo 102, o 
no fuese consciente de que renuncia a su derecho de desistimiento al dar dicho consentimiento; o bien, según los casos, cuando el empresario no hubiese facilitado la confirmación con arreglo al art.98,7 TRDCU (art.108,4 TRDCU).

Por último, si el consumidor hubiese optado expresamente por una modalidad de entrega diferente a la modalidad menos costosa de entrega ordinaria estará obligado a soportar los costes adicionales que de ello se deriven (arts. 107,2 y 108,5 TRDCU).

\subsection{CONSECUENCIAS DERIVADAS DEL EJERCICIO DE LA FACULTAD DE DESISTIMIEN- TO SOBRE LOS CONTRATOS COMPLEMENTARIOS}

Según se infiere del tenor literal del art.76 bis TRDCU, el ejercicio, por parte del consumidor de su derecho de desistimiento conforme a lo previsto en el TRDCU, tendrá por efecto la extinción automática y sin coste alguno para él de todo contrato complementario, excepto en aquellos casos en los que, sin perjuicio de su extinción automática, el consumidor debiera asumir los costes previstos en los artículos 107,2 y 108 del TRDCU.

En este sentido, la Directiva 2011/83/UE nos ofrece, en su art.2,15, un concepto bastante amplio de lo que debemos considerar como contrato complementario pues define a tal contrato como aquel "por el cual el consumidor adquiere bienes $o$ servicios relacionados con un contrato a distancia ... y dichos bienes o servicios son proporcionados por el comerciante o por un tercero sobre la base de un acuerdo entre dicho tercero y el comerciante". Así pues, podemos encuadrar dentro de la categoría de contrato complementario no sólo a los contratos de crédito o financiación celebrados por el consumidor a fin de financiar la adquisición de bienes o servicios mediante la celebración de contratos celebrados a distancia, sino, también, a cualquier otro contrato que permita al consumidor obtener bienes o servicios del propio empresario, o de un tercero con el que aquél haya llegado a un acuerdo previo, que se puedan considerar accesorios de la prestación principal obtenida por el consumidor en virtud del contrato principal celebrado a distancia. Así, por ejemplo, se podría considerar como contrato complementario o accesorio el contrato de prestación de un servicio de mantenimiento, por parte del propio empresario o de un tercero sobre la base un acuerdo previo con aquél, del vehículo que el consumidor hubiese adquirido por medio de un contrato celebrado a distancia. En consecuencia, el desistimiento por parte del consumidor del contrato principal de compraventa del vehículo conllevaría la automática resolución del contrato accesorio o complementario de mantenimiento del mismo.

De conformidad con lo dispuesto en el ya citado art.76, bis TRDCU, ejercido el derecho de desistimiento sobre el contrato principal, las partes deberán restituirse reciprocamente las prestaciones recibidas en virtud del contrato complementario, sin ninguna demora indebida y, en cualquier caso, antes de que hayan 
transcurrido 14 días naturales desde la fecha en que el consumidor hubiese informado al empresario de su decisión de desistir del contrato principal.

En el supuesto de que el empresario no reintegrara todas las cantidades abonadas por el consumidor en virtud del contrato complementario en el plazo señalado o bien no lograra probar tal circunstancia, el consumidor podría reclamar que se le pagara el doble de la suma adeudada, sin perjuicio a su derecho de ser indemnizado por los daños y perjuicios sufridos en lo que excedan de dicha cantidad.

Igualmente, además del reintegro de las cantidades abonadas, el consumidor tendrá derecho al reembolso de los gastos necesarios y útiles que hubiera realizado en el bien.

Por el contrario, en el supuesto de que al consumidor le fuera imposible devolver la prestación objeto del contrato complementario por pérdida, destrucción u otra causa que le sea imputable, deberá responder del valor de mercado que hubiera tenido la prestación en el momento del ejercicio del derecho de desistimiento, salvo que dicho valor fuera superior al precio de adquisición, en cuyo caso responderá de éste.

No obstante, cuando el empresario hubiera incumplido el deber de información y documentación sobre el derecho de desistimiento del contrato principal, la imposibilidad de devolución sólo será imputable al consumidor y usuario cuando éste hubiera omitido la diligencia que le es exigible en sus propios asuntos.

\subsection{EXCEPCIONES AL DERECHO DE DESISTIMIENTO}

Excepcionalmente, según establece el art.103 TRDCU, el consumidor no dispondrá de la facultad de desistir del contrato celebrado a distancia cuanto el mismo tenga por objeto:

a) La prestación de servicios, una vez que el servicio haya sido completamente ejecutado, cuando la ejecución haya comenzado, con previo consentimiento expreso del consumidor y con el reconocimiento por su parte de que es consciente de que, una vez que el contrato haya sido completamente ejecutado por el empresario, habrá perdido su derecho de desistimiento; b) El suministro de bienes o la prestación de servicios cuyo precio dependa de fluctuaciones del mercado financiero que el empresario no pueda controlar y que puedan producirse durante el periodo de desistimiento; c) El suministro de bienes confeccionados conforme a las especificaciones del consumidor y usuario o claramente personalizados; d) El suministro de bienes que puedan deteriorarse o caducar con rapidez.; e) El suministro de bienes precintados que no sean aptos para ser devueltos por razones de protección de la salud o de higiene y que hayan sido desprecintados tras la entrega; f) El suministro de bienes que después de su entrega y teniendo en cuenta su naturaleza se hayan mezclado de forma indisociable con otros bienes; g) El suministro de bebidas alcohólicas cuyo precio haya sido acordado en el momento 
de celebrar el contrato de venta y que no puedan ser entregadas antes de 30 días, y cuyo valor real dependa de fluctuaciones del mercado que el empresario no pueda controlar; h) Los contratos en los que el consumidor haya solicitado específicamente al empresario que le visite para efectuar operaciones de reparación o mantenimiento urgente. No obstante, si, en esa visita, el empresario presta servicios adicionales a los solicitados específicamente por el consumidor o suministra bienes distintos de las piezas de recambio utilizadas necesariamente para efectuar las operaciones de mantenimiento o reparación, el derecho de desistimiento debe aplicarse a dichos servicios o bienes adicionales; i) El suministro de grabaciones sonoras o de vídeo precintadas o de programas informáticos precintados que hayan sido desprecintados por el consumidor y usuario después de la entrega; j) El suministro de prensa diaria, publicaciones periódicas o revistas, con la excepción de los contratos de suscripción para el suministro de tales publicaciones; k) Los contratos celebrados mediante subastas públicas; 1) El suministro de servicios de alojamiento para fines distintos del de servir de vivienda, transporte de bienes, alquiler de vehículos, comida o servicios relacionados con actividades de esparcimiento, si los contratos prevén una fecha o un periodo de ejecución específicos; $\mathrm{m}$ ) El suministro de contenido digital que no se preste en un soporte material cuando la ejecución haya comenzado con el previo consentimiento expreso del consumidor y usuario con el conocimiento por su parte de que en consecuencia pierde su derecho de desistimiento.

\section{EJECUCIÓN DE LOS CONTRATOS CELEBRADOS A DISTANCIA}

Salvo que las partes hayan acordado otra cosa, el empresario deberá ejecutar el pedido sin ninguna demora indebida y a más tardar en el plazo de 30 días naturales a partir de la celebración del contrato (art.109 TRDCU).

En el supuesto de que no se ejecute el contrato por parte del empresario debido a que no se encuentre disponible el bien o servicio contratado, el consumidor deberá ser informado de esta falta de disponibilidad y podrá recuperar sin ninguna demora indebida las sumas que haya abonado en virtud del mismo. Si el empresario se retrasara injustificadamente en la devolución de dichas cantidades adeudadas, el consumidor podrá reclamar que se le pague el doble del importe adeudado, sin perjuicio de su derecho a ser indemnizado por los daños y perjuicios sufridos en lo que excedan de dicha cantidad (art.110 TRDCU).

No obstante, en el supuesto de que el consumidor hubiese sido informado expresamente, podrá el empresario, ante la falta de disponibilidad de bien o servicio contratado, sustituir el mismo por otro bien o servicio de características similares al contratado, que tenga la misma o superior calidad y sin que ello suponga un aumento del precio que deba abonar el consumidor (art.111 TRDCU).

Finalmente, si el consumidor abona el importe de la compra realizada mediante el empleo de una tarjeta de crédito, deberá indemnizar al empresario por los daños y perjuicios que le ocasione la anulación de dicha compra, a no ser que la 
misma fuese consecuencia del ejercicio por el consumidor de su facultad de desistir del contrato celebrado a distancia.

Sin embargo, cuando el importe de una compra o de un servicio hubiese sido cargado fraudulenta o indebidamente utilizando el número de la tarjeta de crédito del consumidor, éste podrá exigir la inmediata anulación del cargo, debiéndose realizar, a la mayor brevedad posible, las correspondientes anotaciones de adeudo y reabono en las cuentas del empresario y del consumidor titular de la tarjeta (art.112 TRDCU).

\section{Bibliografía}

AA.VV., Derecho (privado) de los consumidores, coord. MIRANDA SERRANO, PAGADOR LÓPEZ, Marcial Pons, Madrid, Barcelona, Buenos Aires, 2012;

BERCOVITZ, A., «Modalidades especiales de venta y protección del consumidor», EC, núm. 4, 1985, p. 57 ss.;

LETEACHIRICA, J., «La propuesta de Directiva sobre derechos de los consumidores: ¿nihil novum sub sole?», en AA.VV., Estudios jurídicos en memoria del profesor José Manuel Lete del Río, coord. García Rubio, Civitas, Madrid, 2009, pp. 493 a 512 ;

MIRANDA SERRANO, L. M., "Contratos celebrados a distancia», en AA.VV., La defensa de los consumidores y usuarios. Comentario sistemático del TRDCU, dir. REBOLLO PUIG/IZQUIERDO CARRASCO, Iustel, Madrid, 2011, pp. 1443 a 1562 ;

MIRANDA SERRANO, L., M., «La contratación a distancia de consumo: TRDCU y Directiva 2001/83/UE», en AA.VV., Derecho (privado) de los consumidores, coord. MIRANDA SERRANO, PAGADOR LÓPEZ, Marcial Pons, Madrid, Barcelona, Buenos Aires, 2012, p. 145 a 181;

MIRANDA SERRANO, L., «La Directiva 2011/83/UE sobre derechos de los consumidores: una nueva regulación para Europa de los contratos celebrados a distancia y extramuros de los establecimientos mercantiles», RcD, núm. 11, 2012, pp. 77 a 133;

MIRANDA SERRANO, L./PANIAGUA ZURERA, M., «La protección de los consumidores y usuarios en la fase previa a la contratación: la tutela de la libertad negocial», en AA.VV., Derecho (privado) de los consumidores, coord. MIRANDA SERRANO, PAGADOR LÓPEZ, Marcial Pons, Madrid, Barcelona, Buenos Aires, 2012, pp. 63 a 98 ;

TOBÍO RIVAS, A. M., «Contratos celebrados fuera de los establecimientos mercantiles y contratos a distancia», en AA.VV., Contratos mercantiles especiales, Cuadernos de Derecho Judicial, Madrid, 1997, pp. 37 ss. 